\title{
INTEGRATION OF THE BEAM SCRAPER AND PRIMARY COLLIMATOR IN THE SNS RING
}

\author{
H. Ludewig, N. Simos, D. Davino*, S. Cousineau+, N. Catalan-Lasheras**, J. Brodowski, \\ J. Touzzolo, C. Longo, B. Mullany, and D. Raparia \\ Brookhaven National Laboratory, Upton, New York, 11973, USA \\ *Univesita' del Sannio, Benevento, Italy \\ +Oak Ridge National Laboratory, Oak Ridge, Tennessee, USA. \\ ** CERN, 1211 Geneva 23, Switzerland
}

\begin{abstract}
The collimation system in the SNS ring includes a twostage collimator consisting of a halo scraper and an appropriate fixed aperture collimator. This unit is placed between the first quadru-pole and the first doublet in the collimation straight section of the ring. The scraper is situated at the exact mid-point between these two magnets, and the fixed aperture collimator fills the space between the scraper and the doublet magnet. The scraper and collimator are surrounded by an outer shield structure. The downstream dose to the doublet and the attached corrector magnet will be estimated for normal operating conditions. In addition, the cooling water activation will be estimated. Finally, the dose at the flange locations will be estimated following machine shutdown.
\end{abstract}

\section{INTRODUCTION}

A two-stage halo cleaning system, consisting of a beam scraper and primary fixed aperture collimator are placed between the first quadru-pole and the first doublet in the collimation straight. Halo particles that are intercepted by the scrapers undergo sufficient Coulomb scattering to either deflect them directly into the primary collimator or one of the other collimators in the collimation straight. If the scattered particles are not intercepted on the first pass they will generally be intercepted within the next few circuits around the ring. The scraper is placed at the midpoint between these magnets, and the collimator is placed between the scraper and the doublet. A schematic of the configuration described above is shown on Figure 1. The scrapers will be placed at approximately $140 \pi \mathrm{mm}-\mathrm{mrad}$, and the fixed aperture of the collimator will be at approximately $300 \pi \mathrm{mm}$-mrad. The beam shape at this position is highly elliptical, and thus the beam tube of the collimator will be elliptical with $y / 2=48 \mathrm{~mm}$, and $\mathrm{x} / 2=79$ $\mathrm{mm}$, respectively. The length of the elliptical section of the collimator tube is $1.8 \mathrm{~m}$, and the overall length including transition pieces and end shielding is $2.463 \mathrm{~m}$.

All flux, and heat deposition were determined by the MCNPX code [1]. The activation estimates were carried out using fluxes determined by MCNPX, nuclear data from the CINDER90 library [2], and transmutation determinations by a suitably modified version of the ORIGEN code [3].

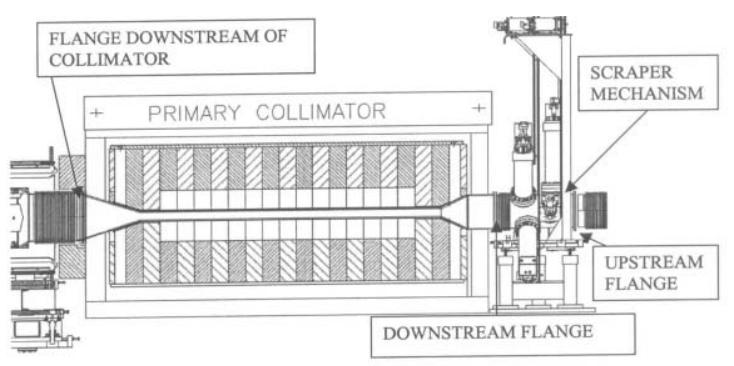

Figure 1: Beam scraper and fixed aperture primary collimator

The scraper consists of tantalum pieces $0.5 \mathrm{~cm}$ thick in the direction of the beam, $1.0 \mathrm{~cm}$ high, and $5.0 \mathrm{~cm}$ wide. This piece is welded to a water-cooled copper block, which in turn is attached to a mechanism to allow motion in and out of the beam. Figure 2 shows a detail of the scraper mechanism. The four scraper surfaces, chain drives, motors, and vacuum chamber can be seen. The scraper mechanism is mounted on three pins, which in turn are attached to a pedestal. Each scraper is individually cooled, and the water temperature, flow rate, and pressure are monitored. The fixed aperture collimator consists of a double walled Inconel-718 [4] tube, surrounded by a water-cooled bed of stainless steel spheres, which in turn is surrounded by a stainless steel shield. This entire configuration is contained in a pressure vessel. Cooling water flows through the particle bed cooling both the spheres and the outer surface of the outer Inconel-718 collimator tube. The space between the inner and outer Inconel-718 tubes is filled with pressurized helium and a copper wire wrap. The scraper mechanism and the collimator will be mounted on a common pedestal in order to ensure alignment, regardless of floor motion. Both components are enclosed in an outer iron shield that reduces dose to the tunnel environment during operation. Due to the proximity of the shield to the magnet, nonmagnetic material must be used in this location.

The loss distribution of scattered particles along the inner surface of the collimator tube is required to determine the resulting doses to surrounding components and is given as a percentage of the particles lost on the tube surface in 


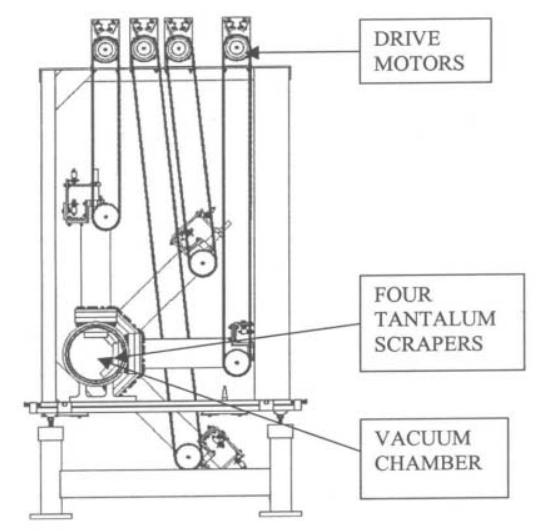

Figure 2: Beam scraper mechanism

Figure 3. It is seen that there is a relatively high loss ( $10 \%)$ at the entrance to the collimator, and the bulk of the collimator has a relatively constant loss of $\sim 4.4 \%$. This loss profile is used as input to the Monte Carlo code MCNPX.

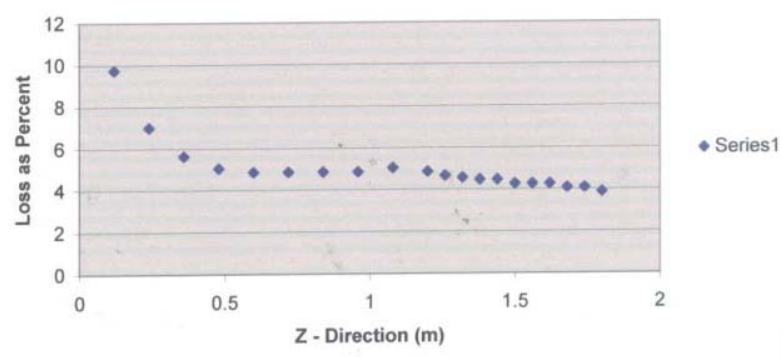

Figure 3: Primary collimator loss profile

\section{RESULTS}

In this section we will discuss the estimated results of doses to the flange areas on either side of the collimator and scrapers, to the scraper drive motors, and the downstream magnets. In addition the activation of the components, and subsequent dose to the flange areas due to decay gamma-rays following machine shutdown, will be estimated. The loss fraction under normal operating conditions in the ring is assumed to be 0.001 of the circulating beam; of this, $5 \%$ is lost on the scrapers, and $30 \%$ is lost on the inner surface of the primary collimator. Thus, the loss fraction on the scrapers is 0.00005 , and the loss fraction on the collimator is 0.0003 . Furthermore, the assumption will be made that the machine is operating at $2 \mathrm{MW}$ for one year (defined as 250 days, or $2.16 \times 10^{7}$ seconds).

During normal operation of the machine the dose for one year is given below at the four locations of interest.
Table 1: Dose to Flanges while Machine is Operating $(\mathrm{rad} / \mathrm{yr})$

\begin{tabular}{|l|c|c|c|}
\hline $\begin{array}{c}\text { Location } \\
\text { Description }\end{array}$ & $\begin{array}{c}\text { Collimator } \\
\text { Dose }\end{array}$ & $\begin{array}{c}\text { Scraper } \\
\text { Dose }\end{array}$ & $\begin{array}{c}\text { Total } \\
\text { Dose }\end{array}$ \\
\hline $\begin{array}{l}\text { Flange } \\
\text { upstream of } \\
\text { scraper }\end{array}$ & $1.20(5)^{*}$ & $1.71(6)$ & $1.83(6)$ \\
\hline $\begin{array}{l}\text { Flange } \\
\text { downstream of } \\
\text { scraper }\end{array}$ & $4.87(5)$ & $7.54(6)$ & $8.03(6)$ \\
\hline $\begin{array}{l}\text { Flange } \\
\text { downstream of } \\
\text { collimator }\end{array}$ & $2.47(7)$ & $\sim$ & $2.47(7)$ \\
\hline $\begin{array}{l}\text { Magnet } \\
\text { downstream of } \\
\text { collimator }\end{array}$ & $4.83(7)$ & $\sim$ & $4.83(7)$ \\
\hline \multicolumn{2}{|l|}{$* 1.20(5)=1.20 \times 10^{15}$} & \\
\hline
\end{tabular}

Assuming that the magnet insulation is Kapton, and assuming that its life is approximately 2(9) rads, then the magnet life under normal conditions should be $\sim 40$ years. Assuming that the entire ring loss fraction takes place in the primary collimator, or the overall ring loss increases by approximately a factor of three, the dose to the magnet increases to 1.6(8) rads, and the implied life of the magnets would be reduced to $\sim 12$ years.

Following machine shutdown the level of radiation at the flanges is of interest, since they may have to be accessed for maintenance purposes. An estimate was made of the potential dose at the flange locations following one year of operation. The estimated dose at the four locations described above, immediately following shutdown, are given below.

Table 2: Dose to Flanges Following Machine Shutdown

\begin{tabular}{|l|c|}
\hline \multicolumn{1}{|c|}{ Location Description } & $\begin{array}{c}\text { Dose } \\
(\mathrm{mrad} / \mathrm{hr})\end{array}$ \\
\hline Flange upstream of scraper & 84 \\
\hline Flange downstream of scraper & 5025 \\
\hline Flange downstream of collimator & 490 \\
\hline Magnet downstream of collimator & 790 \\
\hline
\end{tabular}

It is seen that the dose to the flange located between the scraper and the collimator is quite high, and a decay period would be advisable before maintenance activities are carried out. If the loss in the ring were concentrated at the primary collimator the dose values would increase by approximately a factor of three.

An estimate of the reduction in the above values following a decay period can be obtained by determining the reduction in activation for both the tantalum scrapers and the stainless steel collimator components. The normalized activation decay for representative volumes of these two components is given below. 
Table 3: Decay of Activation of Tantalum and Stainless Steel Following Machine Shutdown

\begin{tabular}{|l|c|c|c|c|c|}
\hline Material & \multicolumn{5}{|c|}{ Time following machine shutdown } \\
\hline & 0.0 & 4 hrs. & 1 day & 7 days & $\begin{array}{c}30 \\
\text { days }\end{array}$ \\
\hline $\begin{array}{l}\text { Stainless } \\
\text { Steel }\end{array}$ & 1.0 & 0.776 & 0.677 & 0.537 & 0.328 \\
\hline Tantalum & 1.0 & 0.462 & 0.284 & 0.125 & 0.061 \\
\hline
\end{tabular}

These estimates indicate that the collimator will decay at a much slower rate than the scrapers. However, if a decay period of approximately one day is allowed in the maintenance schedule, then the dose should be reduced by $\sim 50 \%$.

The dose to the scraper drive motors while the machine is operating is of concern, since eventually a high enough dose will compromise the motor insulation. Estimates of dose at the motor location were made, assuming that $5 \%$ of the loss occurs on the scrapers, and an iron shield was inserted between the scraper mechanism and the motors. Two values for the shield thickness were assumed, and the corresponding doses estimated. Results are given below, and indicate that an iron shield of nominal thickness implies an acceptable motor life, assuming the same radiation damage resistance as that given above for the magnets. If the loss increases to the maximum ring loss, the dose values increase by a factor of 20 , and the condition of the drive motors should be monitored.

Table 4: Dose to Scraper Drive Motors

\begin{tabular}{|c|c|}
\hline Iron Shield Thickness $(\mathrm{cm})$ & Dose $(\mathrm{rad} / \mathrm{yr})$ \\
\hline 15 & $1.1(5)$ \\
\hline 30 & $5.5(4)$ \\
\hline
\end{tabular}

An estimate was made of the residual activity in the collimator and scraper cooling water immediately after shutdown and following 4 hours of decay time. These estimates assume that the ring loss is confined to the primary collimator and the machine operation for one year. The scraper activity is estimated by scaling off the values obtained for the collimator. Immediately following shutdown, the activity is dominated by the short half-lived isotopes $\mathrm{O}-15, \mathrm{~N}-16, \mathrm{C}-11$, and B-12. After a 4 hour decay period the dominant contributors to the activity are Be-7, and C-14. Note is also taken of $\mathrm{H}-3$, although its total activity is low, and its contribution to the overall activity marginal.

Table 5: Residual Activity of Collimator Cooling Water Four Hours after Machine Shutdown (Curies)

\begin{tabular}{|l|c|}
\hline \multicolumn{1}{|c|}{ Isotope } & Activity \\
\hline Tritium (H-3) & $2.6(-8)$ \\
\hline Beryllium $(\mathrm{Be}-7)$ & $6.1(-2)$ \\
\hline Carbon $(\mathrm{C}-14)$ & $2.2(-5)$ \\
\hline
\end{tabular}

Scraper cooling water activity is a fraction of the above collimator cooling water activity. A direct scaling of the activity by the loss fraction would result in a reduction of the above values by a factor of six. However, this reduction is optimistic, since the collimator water is exposed to the high-energy particles while in the scraper the geometric arrangement essentially precludes this interaction.

\section{CONCLUSIONS}

The following conclusions can be drawn from this study:

1) The loss profile along the fixed aperture collimator is biased to the upstream end, and thus affects the flange between it and the beam scraper.

2) Dose estimates while the machine is operating will require the exchange of the downstream magnets at least once during the life of the machine.

3) Dose to the scraper drive motors is likely to be low enough to ensure that they will operate for the machine life.

4) Maintenance work on the flanges will best be carried out following a decay period of at least one day to one week, in order to reduce the dose to the workers.

\section{REFERENCES}

[1] MCNPX Users Manual-Version 2.1.5, L.S. Waters, ed., Los Alamos National Laboratory, Los Alamos, NM, TPO-E83-G-UG-X-00001 (1999).

[2] W.B. Wilson, "Accelerator Transmutation Studies at Los Alamos with LAHET, MCNP, and CINDER90," Los Alamos National Laboratory, Los Alamos, NM, LA-UR-93-3080 (1993).

[3] A.G. Croff, "ORIGEN2 - A revised and updated version of the Oak Ridge isotope generation and depletion code," Oak Ridge National Laboratory, Oak Ridge, TN (1977).

[4] W. Sommer, R. Werbeck, S. Maloy, M. Borden, and R. Brown, "Materials selection and qualification processes at a high-power spallation neutron source," Materials Characterization, 43, 97 - 123 (1999).

\section{ACKNOWLEDGEMENTS}

SNS is managed by UT-Battelle, LLC, under contract DE-AC05-00OR22725 for the U.S. Department of Energy. SNS is a partnership of six national laboratories: Argonne, Brookhaven, Jefferson, Lawrence Berkeley, Los Alamos and Oak Ridge. 